\title{
Moldes para puñales en la Península Ibérica durante la Edad del Bronce. El caso de Camp Cinzano (Vilafranca del Penedès, Alt Penedès, Barcelona)
}

\author{
Dagger moulds in the Iberian Peninsula during the Bronze Age. The Camp Cinzano site \\ (Vilafranca del Penedès, Alt Penedès, Barcelona province)
}

\author{
Ignacio Soriano (*) \\ Jordi Amorós i Gurrera (**)
}

\section{RESUMEN}

Un molde lítico para puñales fue localizado en un contexto funerario fechado mediante C14 en c. 1850 cal ANE en el asentamiento de la Edad del Bronce de Camp Cinzano (Vilafranca del Penedès, Alt Penedès, Barcelona). Se estudian la tipología y materia prima del molde y las características del artefacto metálico moldeado en el, relacionándolas con la metalurgia del II milenio del nordeste de la Península Ibérica. Se exponen los escasos paralelos de moldes para puñales existentes en la Península Ibérica y en el Mediterráneo Occidental, así como las posibles razones de su ausencia en el registro arqueológico. Los datos sugieren dos lugares de origen para el molde estudiado, el Levante ibérico y el norte de Italia (grupos de Polada). Esta última zona mantiene mayores relaciones e interacciones en el ámbito metalúrgico con el nordeste de la Península Ibérica.

\begin{abstract}
The Bronze Age settlement of Camp Cinzano (Vilafranca del Penedès, Alt Penedès, Barcelona province) yielded a riveted dagger stone mould in a funerary context $C 14$ dated to $c .1850 \mathrm{cal} \mathrm{BC}$. We examine the characteristics of the mould (typology and raw material) and the metal artifact found at the site and relate them to the metallurgy of the $2^{\text {nd }}$ Millennium BC in the Northeastern Iberian Peninsula. We present the few comparable dag-
\end{abstract}

(*) Grupo de Investigación Arqueológica del Nordeste Peninsular (GRANEP) y Dpto. de Prehistoria, Facultad de Filosofía y Letras, Universidad Autónoma de Barcelona. Edificio B. 08193 Bellaterra. Barcelona. España. Correo e.: nachsoriano@hotmail.com

(**) Arqueólogo. Director de la intervención arqueológica de Camp Cinzano 2004-2005. Correo e.: jrd.amoros@gmail.com

Recibido: 16-V-2013; aceptado: 11-X-2013. ger moulds existing in the Iberian Peninsula and the Western Mediterranean and discuss the possible reasons for their rarity in the archaeological record. The data indicate two possible places of origin for the mould studied: the East coast of the Iberian Peninsula and Northern Italy (the Polada group). The latter is an area which exhibits greater interaction and relationships with the Northeastern Iberian Peninsula in the metallurgic sphere.

Palabras clave: Molde de fundición; Arqueometalurgia; Difusión tecnológica; Crisol con perforación para el enmangue; Crisol con pie macizo; Edad del Bronce; Prehistoria Reciente; Mediterráneo Occidental.

Key words: Casting mould; Archaeometallurgy; Technological diffusion; Socketed crucible; Pedestal base crucible; Bronze Age; Late Prehistory; Western Mediterranean.

\section{CAMP CINZANO. ESTRUCTURAS ARQUEOLÓGICAS, MATERIALES Y CRONOLOGÍA}

\subsection{El asentamiento}

El yacimiento de Camp Cinzano se localiza a levante de Vilafranca del Penedès, villa situada en el centro del pasillo natural que forma la Depresión Prelitoral que discurre desde los Pirineos hasta el valle del Ebro (Fig. 1). La zona arqueológica es un solar de 2 ha de forma aproximadamente triangular, localizado entre el muelle de descarga de vagones de RENFE (al este de la estación de Vilafranca) y la carretera de Barcelona N-340 (Fig. 2A). La parte central del solar fue 
rebajada entre 1952 y 1953 para construir la fábrica de la casa italiana de vermut Cinzano, de donde toma el nombre. Entonces se documentaron restos del Neolítico Medio (Sepulcros de Fosa), así como del Bronce Inicial (Bronce Antiguo-Medio) (1). De esta última fase se excavó el llamado 'Sepulcro 1', una cista con una losa de cubierta $(107 \times 90 \mathrm{~cm})$ trabajada en los laterales. Un extremo apoyaba sobre otra losa $(110 \times 75 \mathrm{~cm})$, puesta en posición vertical y sujeta por bloques más pequeños, y el opuesto apoyaba directamente sobre el mismo suelo de la fosa. La inhumación, colocada en posición fetal sobre su lado derecho y con la cara mirando hacia el Sur, descansaba sobre un lecho de cantos planos. El ajuar consistía en una punta de flecha de cobre de cuerpo romboidal sin aletas y con pedúnculo corto (2), un punzón de hueso y un vaso troncocónico con incisiones sobre el labio (Giró 1954; Muñoz 1965: 111-115). En esta primera intervención los callejones de servicio del lado oriental de la fábrica ni se prospectaron, ni se excavaron. Ello sucedió a finales del año 2004 y principios del 2005, durante unos rebajes para la construcción de viviendas, tras la demolición de la fábrica. Entonces se sacó a la luz parte de un asentamiento al aire libre perteneciente al Bronce Inicial. Los resultados de las 3 dataciones C14 disponibles sitúan su utilización c. 1900 y 1550 cal ANE. (Tab. 1). Se engloba entre los asentamientos agrícolas en llanura cuyos ejemplos más conocidos en la Depresión Prelitoral catalana son el cercano de Mas d'en Boixos-1 (Pacs del Penedès) (Bouso et al. 2004) y el complejo de Can Roqueta (Sabadell) (Carlús et al. 2008), ambos en la provincia de Barcelona. Otros similares fue-

(1) El término 'Bronce Inicial', empleado en el nordeste de la Península Ibérica, nació en los 1990 y todavía sigue en uso. Surge ante la imposibilidad de distinguir el Bronce Antiguo del Bronce Medio, quedando el Bronce Final como un período aparte vinculado a los Campos de Urnas (Maya 1991, 1992, 1997; Maya y Petit 1994). Ese período inicial de la Edad del Bronce engloba más de mil años, aparentemente, sin cambios remarcables detectables. En la actualidad gracias a la disponibilidad de un número relevante de fechas $\mathrm{C} 14$ y de yacimientos excavados con metodología arqueológica se está revisando esta periodización. En este artículo mantenemos de modo provisional la genérica denominación de Bronce Inicial.

(2) Según Soriano (2013b: 114-115) corresponde a la variante $2 \mathrm{~B}$. Son puntas sin aletas, de morfología romboidal o foliácea, pedúnculo corto y un grado de esbeltez (long. máxima/ anch. máxima) entre 3 y 3.5. El otro ejemplar de esta variante procede de Cova del Batllevell (Pontons, Alt Penedès), yacimiento muy cercano a Camp Cinzano.
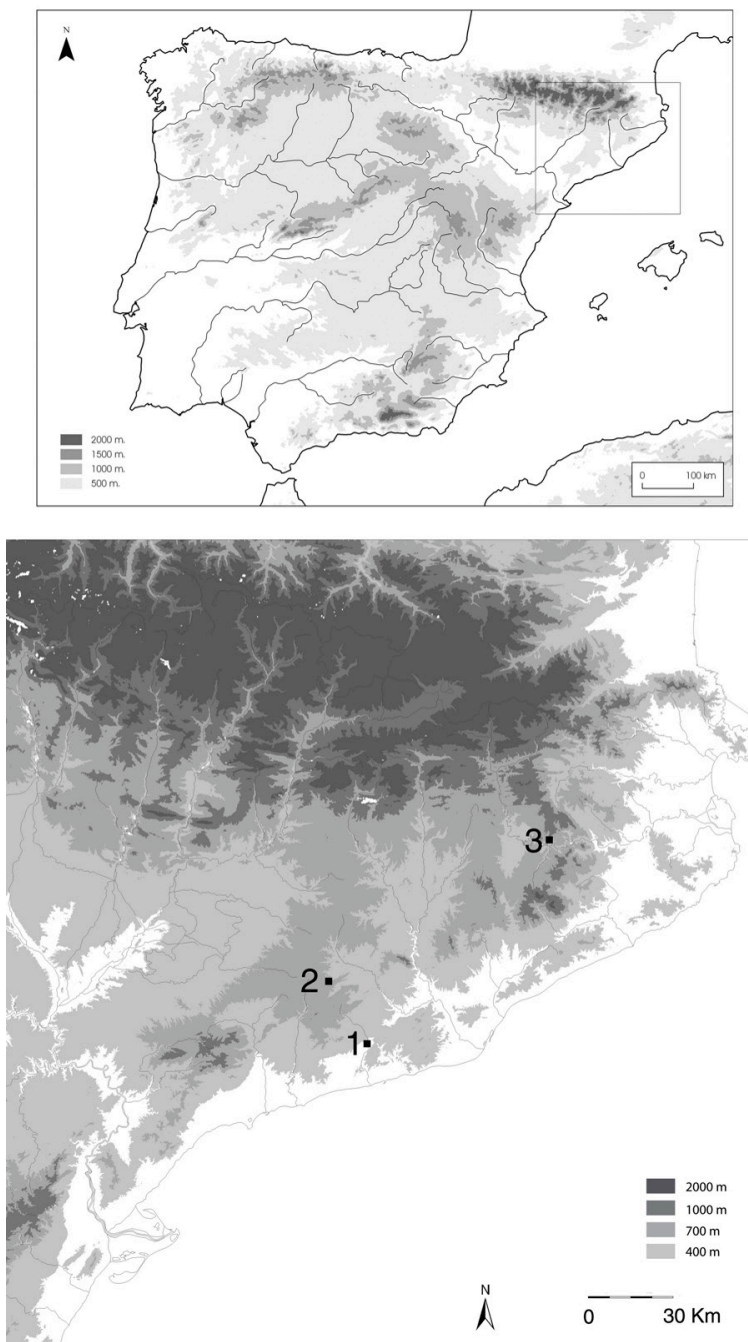

Fig. 1. Localización de Camp Cinzano (n. ${ }^{\circ}$ 1) (Vilafranca del Penedès, Alt Penedès, Barcelona) en la Península Ibérica. Distribución en el nordeste de los yacimientos con puñales de remaches que coinciden morfométricamente con la matriz del molde estudiado: 2. Cova de Mas Vilà (Santa Maria de Miralles, Anoia); 3. Cova de les Grioteres (Vilanova de Sau, Osona).

ra del área prelitoral son el Institut de Batxillerat Antoni Pous (Manlleu, Barcelona) (Boquer et al. 1995), el Camí dels Banys de la Mercè (Capmany, Girona) (Palomo 2006) y los leridanos de Minferri (Juneda) (Equip Minferri 1997) o la Vinya del Corb (Basella) (Piera 2008).

Las estructuras pertenecientes a este horizonte cronocultural de Camp Cinzano están a unos 50$60 \mathrm{~m}$ al este del Sepulcro 1 excavado en 1952. Son 8 silos de almacenaje, 2 silos/fosas, 2 grandes estructuras con recortes ovalados en el fondo 


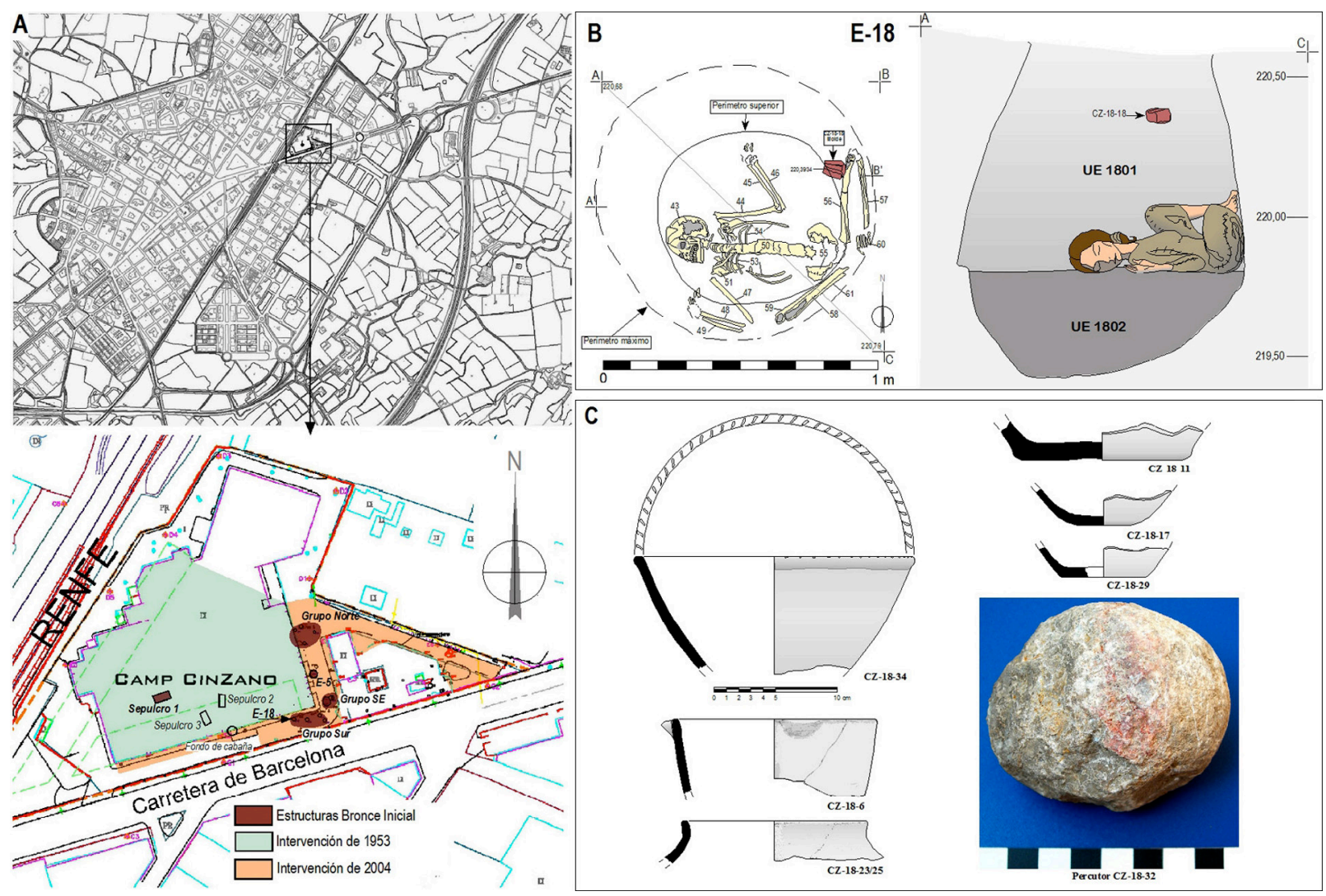

Fig. 2. Camp Cinzano (CZ, Vilafranca del Penedès, Alt Penedès, Barcelona): A. Plano de ubicación del yacimiento en Vilafranca del Penedès y planta general; B. Planta y sección proyectada experimental de la fosa/silo funeraria E-18, donde se observa la desconexión entre el molde y la inhumación; C. Materiales recuperados en la estructura (Amorós 2008).

\begin{tabular}{|c|c|c|c|c|c|}
\hline CÓDIGO LAB & VALOR BP & $\begin{array}{c}\text { VALOR CAL } \\
\text { ANE }\end{array}$ & MUESTRA & CONTEXTO & BIBLIOGRAFÍA \\
\hline UBAR-1007 & $3505 \pm 40$ & 1826 & $\begin{array}{c}\text { Hueso } \\
\text { humano }\end{array}$ & $\begin{array}{c}\text { Fosa/silo funerario E-18, } \\
\text { UE-1801 }(1 \text { ind. })\end{array}$ & Soriano 2010: 746 \\
\hline UBAR-861 & $3450 \pm 40$ & 1775 & Fauna & Silo E-16, UE-1602 & Amorós 2008 \\
\hline LTL-2451A & $3333 \pm 35$ & 1609 & $\begin{array}{c}\text { Hueso } \\
\text { humano }\end{array}$ & $\begin{array}{c}\text { Fosa/silo funerario E-7, } \\
\text { UE-706 }(1 \text { ind. })\end{array}$ & Amorós 2008 \\
\hline
\end{tabular}

Tab. 1. Camp Cinzano (Vilafranca del Penedès, Alt Penedès, Barcelona). Dataciones absolutas (programa empleado Calib 5.0). El valor calibrado es el resultado de la media de la datación calibrada a $1 \sigma$ ponderada por cada uno de los rangos de valores probables existentes (Soriano 2013b: 5). Lab.=Laboratorio; Ind.= Individuo.

y 1 fosa ovalada de función indeterminada. A la vista de la distribución de las estructuras y de los espacios estériles que las rodean, Camp Cinzano parece un asentamiento que combinaría estructuras aéreas de habitación y de producción con una decena (quizás más) de estructuras subterráneas de almacenamiento, concentradas en un área de unos $50 \mathrm{~m}$ de diámetro. El gran recorte E-5, interpretado como punto de extracción de materia prima para la construcción de cabañas, habría ocupado el núcleo central. Presumiblemente los rebajes realizados en 1952 habrían destruido parte de su lado occidental. La estructura fue posteriormente rellenada hasta cierto nivel con tierras 
orgánicas y escombros para su reaprovechamiento bien para una producción indeterminada (tal como indican los restos de tres hogares en un mismo nivel de uso), bien como hábitat. La construcción de hábitats de tierra y entramado vegetal queda atestiguada en Camp Cinzano por los numerosos restos de torchis amortizados en los silos con otros materiales. Los torchis aparecen frecuentemente en yacimientos contemporáneos relativamente cercanos (3) (Pancorbo y Piera 2006). Los silos E-6, E-7 y E-18 se reutilizaron como tumbas individuales sin ajuar de personas de diferentes edades y sexos. Entre los materiales arqueológicos recuperados en todo el ámbito del asentamiento destaca la cerámica genérica del Bronce Inicial con un número mínimo de más de cien individuos. Hay decoraciones incisas; cordones lisos, incisos e impresos, y lengüetas y mamelones sobre recipientes, en general, de morfología ovoide y cilíndrica con base plana. Destaca un fragmento de vaso geminado, al que más adelante haremos referencia, así como la falta de decoraciones epicampaniformes y de vasos con apéndice de botón. La industria lítica se reduce a unas pocas láminas de sílex, un fragmento de molino y varios alisadores $\mathrm{y} / \mathrm{o}$ percutores. La ósea se limita a un punzón y a un alisador para el curtido de la piel. Además de la punta de flecha del Sepulcro 1 hay un punzón metálico de sección cuadrada procedente del nivel de uso de los tres hogares de la estructura E-5. No obstante, la capacidad de producción metalúrgica del asentamiento queda atestiguada por la presencia del molde lítico para puñales de remaches objeto de este estudio (Amorós 2008).

\subsection{El contexto del hallazgo}

El molde fue hallado en la fosa/silo E-18, perteneciente al denominado Grupo Sur de estructuras. En origen era un silo de sección ovoidal reaprovechado tras su amortización como lugar de enterramiento (Fig. 2B). El inhumado, cuyo sexo no ha podido ser determinado, tenía entre 15 y 20 años. Se descompuso en espacio colmatado según se deduce de la disposición de las

(3) Vicente, J. M. a y Gutiérrez, D. Memòria de la intervenció a l'Escola Bressol de la Florida Nord (Sta Perpètua de la Mogoda, Vallès Occidental). Servei d'Arqueologia i Paleontologia, Generalitat de Catalunya. Manresa, 2004. articulaciones y la posición aparentemente forzada del cuerpo, con las piernas apoyadas en la pared vertical de la fosa. Esta postura inusual ha sugerido que sujetaron al cadáver por los pies colgándole desde el exterior y soltándole cuando la cabeza y la espalda tocaron al suelo. El que fuera un estrato de superficie plana y prácticamente estéril favorece la idea de que sirviera como lecho deliberado para acoger el cadáver. La causa de la muerte parece haber sido una enfermedad aguda (Subirà 2008), quizás infecciosa o de efectos letales tan rápidos que obligó a la comunidad a depositar rápidamente el cuerpo sin otro cuidado especial. No se encontró ajuar. Una datación C14 sitúa su muerte c. 1850 cal ANE (UBAR-1007). El molde, como el resto de materiales documentados, se halló en el estrato de arcillas grisáceas que cubría la inhumación. Entre los abundantes restos domésticos amortizados que contenía destacan un diente de ovicáprido, un percutor de caliza y un borde de vaso troncocónico muy parecido al encontrado en el Sepulcro 1 (Fig. 2C), materiales que, evidentemente, no pueden ser considerados un ajuar funerario. Este estrato debe datarse en un momento muy cercano a la inhumación, ya que los huesos humanos no presentan desplazamientos que indiquen una descomposición en vacío (Subirà 2008). Los datos disponibles sobre estructuras negativas de este período, excavadas en el área de estudio, también constatan el carácter sincrónico de la inmensa mayoría de los estratos que las rellenan (Bouso et al. 2004). La fecha absoluta obtenida en la estructura puede suponerse, por tanto, cercana al momento de uso del molde. Esta fecha coincide con las obtenidas para otros moldes y evidencias metalúrgicas del nordeste de la Península Ibérica (Tab. 2).

\section{EL MOLDE. DESCRIPCIÓN, CARACTERÍSTICAS Y ANÁLISIS}

El molde lítico de Camp Cinzano es el único de sus características conocido hasta el momento en el área catalana (Fig. 3). Ello se debe a su peculiar matriz, que adopta la morfología de un puñal de remaches y de la que hablaremos más adelante. El molde es univalvo cerrado o de alimentación vertical. Es un tipo compuesto por una única valva con la matriz tallada del objeto a obtener y una tapa lisa ajustable (Fraile 2011: 


\begin{tabular}{|c|c|c|c|c|c|c|c|}
\hline $\begin{array}{l}\text { YACI- } \\
\text { MIENTO }\end{array}$ & $\begin{array}{l}\text { OBJ. MET. } \\
\text { ASOCIADO }\end{array}$ & $\begin{array}{l}\text { CÓDIGO } \\
\text { LAB }\end{array}$ & VALOR BP & $\begin{array}{l}\text { VALOR } \\
\text { CAL ANE }\end{array}$ & MUESTRA & CONTEXTO & BIBLIOGRAFÍA \\
\hline Minferri & Crisol & UBAR-551 & $3660 \pm 280(*)$ & 2091 & Carbón & $\begin{array}{l}\text { Silo SJ-55, } \\
\text { UE-7010 }\end{array}$ & $\begin{array}{l}\text { Equip Minferri } \\
\text { 1997: 197; Rovira } \\
\text { Hortalà } 1998\end{array}$ \\
\hline Cueva Maja & $\begin{array}{l}2 \text { Punzones } \\
\text { de bronce }\end{array}$ & GrN-18067 & $3665 \pm 40$ & 2055 & Carbón & Hogar, la Sala & $\begin{array}{c}\text { Samaniego et al. } \\
\text { 2001: } 91\end{array}$ \\
\hline Minferri & $\begin{array}{l}\text { Restos de colada } \\
\text { de bronce }\end{array}$ & UBAR-548 & $3590 \pm 110$ & 1942 & Carbón & $\begin{array}{l}\text { Silo SJ-33, } \\
\text { UE-5034 }\end{array}$ & GIP 2002: 18 \\
\hline Monte Aguilar & $\begin{array}{l}4 \text { Punzones } \\
\text { de bronce }\end{array}$ & I-16809 & $3510 \pm 100$ & 1835 & Carbón & $\begin{array}{l}\text { Sector B, } \\
\text { nivel VII }\end{array}$ & $\begin{array}{c}\text { Sesma y García } \\
\text { 1994: } 278\end{array}$ \\
\hline Minferri & Molde & UBAR-549 & $3510 \pm 60$ & 1827 & Carbón & $\begin{array}{l}\text { Silo SJ-53, } \\
\text { UE-707 }\end{array}$ & GIP 2002: 18 \\
\hline Monte Aguilar & $\begin{array}{l}2 \text { Punzones } \\
\text { de bronce }\end{array}$ & GrN-19671 & $3510 \pm 20$ & 1822 & Carbón & $\begin{array}{l}\text { Sector A, } \\
\text { Fase VA }\end{array}$ & $\begin{array}{c}\text { Sesma y García } \\
\text { 1994: } 278\end{array}$ \\
\hline Minferri & 2 Crisoles & Beta-92280 & $3410 \pm 90$ & 1730 & Fauna & $\begin{array}{c}\text { Fosa/silo } \\
\text { funerario SJ-88 } \\
\text { UE-2121 (2 ind.) }\end{array}$ & $\begin{array}{c}\text { Equip Minferri } \\
\text { 1997: } 197\end{array}$ \\
\hline Can Roqueta II & Molde & UBAR-800 & $3360 \pm 70$ & 1641 & Fauna & $\begin{array}{c}\text { Cámara con pozo } \\
\text { de acceso } \\
\text { CRII-36, capa } 4 \\
\text { (2 ind.) }\end{array}$ & $\begin{array}{c}\text { Carlús et al. 2008: } \\
119\end{array}$ \\
\hline $\begin{array}{l}\text { Forat de la } \\
\text { Tuta }\end{array}$ & 3 Moldes & LTL-4236A & $3335 \pm 45$ & 1615 & $\begin{array}{l}\text { Hueso huma- } \\
\text { no }\end{array}$ & $\begin{array}{l}\text { Tumba de } \\
\text { metalúrgico } \\
\text { (1 ind.) }\end{array}$ & Soriano 2011: 42 \\
\hline
\end{tabular}

Tab. 2. Dataciones absolutas relacionadas con la producción metalúrgica y/o con los primeros objetos de bronce en la Península Ibérica (programa empleado Calib 5.0, véase Tab. 1). En cursiva, yacimientos del nordeste: Minferri (Juneda, Garrigues, Lleida); Cueva Maja (Cabrejas del Pinar, Soria); Monte Aguilar (Bárdenas Reales, Navarra); Can Roqueta II (Sabadell, Vallès Occidental, Barcelona); Forat de la Tuta (Riner, Solsonès, Lleida). Obj. met.=objetos metálicos o metalúrgicos; Lab.=Laboratorio; $(*)=$ Datación cuya desviación típica, demasiado amplia, aconseja excluirla.

171). El ejemplar aquí descrito es de morfología paralelepípeda. Solo conserva la valva, fragmentada por las partes superior e interior. Sus dimensiones conservadas (en mm) son 76 de long., 69 de anch. máxima, 33 de esp. y 3 de profundidad de la matriz (Fig. 4). Está depositado en el VINSEUM - Museo de las Culturas del Vino de Cataluña ( . $^{\circ}$ inv. CZ/E18/18) con el resto de materiales de Camp Cinzano.

Este tipo de moldes debe colocarse necesariamente en posición vertical durante el vertido. El bebedero suele coincidir con la parte proximal del objeto a obtener, en este caso la lengüeta del puñal. Como solo se ha conservado la parte central del molde, no podemos afirmarlo con rotundidad. La pieza pudo sostenerse e inmovilizarse según métodos no excluyentes entre sí: la intro-

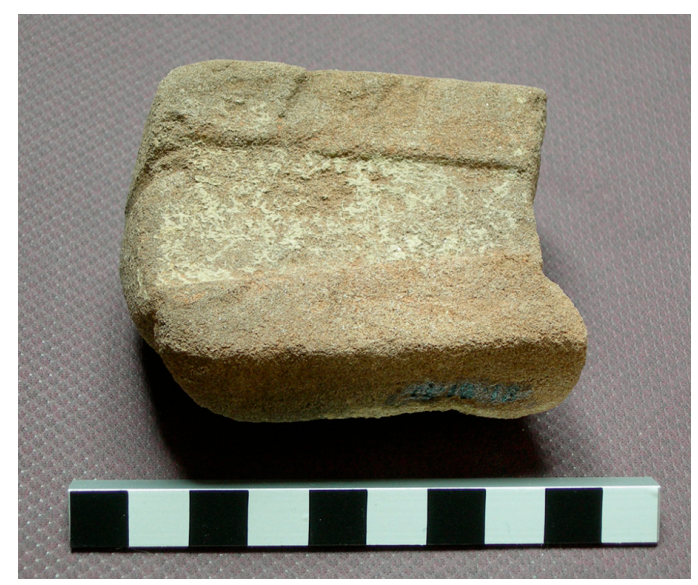

Fig. 3. Molde para puñales de Camp Cinzano (Vilafranca del Penedès, Alt Penedès, Barcelona) (fotografía Jordi Amorós). 


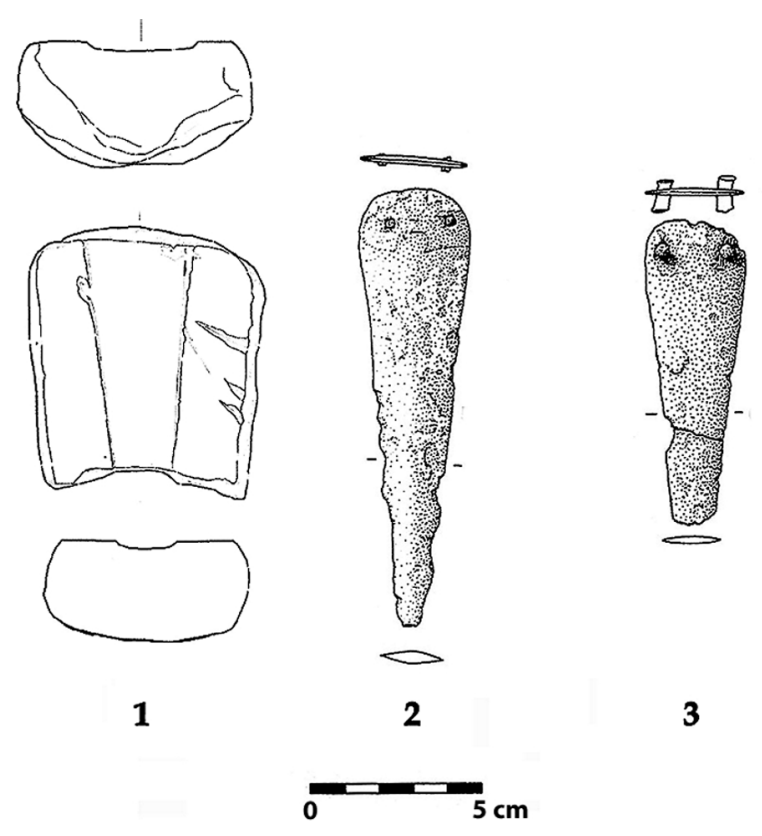

Fig. 4. Molde para puñales de Camp Cinzano (Vilafranca del Penedès, Alt Penedès, Barcelona) (n. ${ }^{\circ} 1$, Amorós 2008: 117) y coincidencia morfométrica con puñales de remaches del nordeste: 2. Cova de les Grioteres (Vilanova de Sau, Osona); 3. Cova de Mas Vilà (Santa Maria de Miralles, Anoia)(Brandherm 2003: n. 526 y 326).

ducción en un orificio excavado en el suelo, el empleo de arena o piedras o la sujeción con ataduras posiblemente de origen vegetal. Algunos de estos sistemas han sido constatados en yacimientos de la Edad del Bronce como Peña Negra (Crevillente, Alicante) (4), Forat de la Tuta (Riner, Lleida) (Soriano 2011: 40) y Lède du Gurp en Grayan-et-1'Hospital (Aquitania, Francia) (Roussot-Larroque 1997: 44). El material empleado es la arenisca con propiedades muy adecuadas para estos útiles metalúrgicos. Esta piedra relativamente blanda, poco quebradiza, permite acabados muy depurados y abunda en la naturaleza. Su gran resistencia al impacto térmico contrasta con la rápida velocidad de enfriamiento, característica poco adecuada para conseguir útiles con buenas propiedades mecánicas (Ottaway y Wang 2004: 81-84). Para solventar este problema el molde se calienta antes del vertido, introdu-

(4) Fraile, A. Moldes de fundición de la Edad del Bronce en la Península Ibérica: Ensayo tipológico y cartográfico. Trabajo de Investigación de Tercer Ciclo, Universidad de Valladolid, 2007. ciéndolo en un lecho de brasas, carbón o arena caliente. La termoalteración presente en el interior (alrededores de la matriz) y en el exterior del molde estudiado podría relacionarse con este procedimiento. Los datos experimentales han demostrado que la termoalteración en los moldes es un buen indicador de su uso. Sin embargo, su ausencia no excluye su empleo, dado que la alteración puede desaparecer con el paso del tiempo (Craddock et al. 1997). En general, los moldes de piedra son más duraderos que los de arcilla, lo que permite su sucesiva reutilización.

El molde de Camp Cizano no difiere por su tipo (univalvo cerrado), ni por la materia prima empleada (arenisca) de los 20 documentados en el nordeste de la Península Ibérica (Rovira Hortalà et al. 2007; Soriano 2013b: 66-70). No se puede decir lo mismo de la matriz para puñal de remaches. Las demás corresponden invariablemente a hachas, varillas o cinceles/escoplos. La excepcionalidad de la de Camp Cinzano no genera dudas sobre su identificación. La morfometría de la matriz ha sido comparada con la de los objetos metálicos contemporáneos y la coincidencia se reduce a la de los puñales de remaches, en su gran mayoría de bronce. Se detecta una gran similitud con los ejemplares de Cova de Mas Vilà (Sta. Maria de Miralles) y Cova de les Grioteres (Vilanova de Sau), ambos en la provincia de Barcelona (Fig. 4). El reciente estudio de los puñales de remaches en el área catalana no ha detectado variabilidad en las proporciones (relación long. máxima/ anch. máxima) aunque sí en las dimensiones absolutas (Soriano 2013b: 107). Esta consideración hace altamente probable la obtención de uno o ambos puñales en el molde señalado. La distancia de Cova de Mas Vilà respecto a Camp Cinzano es escasa, pero la de Cova de les Grioteres alcanza casi los $100 \mathrm{~km}$.

Desconocemos si el molde presentaba orificios o elementos en positivo vinculados a la introducción de remaches, aunque creemos más plausible que no los tuviera. Los ejemplos que conocemos de moldes univalvos de puñales carecen de orificios mientras que su presencia es más común en los bivalvos (véase infra). A falta de otros datos nos decantamos por una producción a posteriori de los remaches, perforando la hoja con un útil de mayor dureza que el metal. Los remaches deberían ser más dúctiles que el objeto remachado, tanto para facilitar su alojamiento en frío como para sujetar correctamente la hoja sin 
llegar a dañarla o romperla (Coghlan 1975: 117). Los escasos remaches metalografiados y/o con pruebas de microdureza de la Península Ibérica no aportan datos concluyentes. Muchos muestran tratamientos postfundición de endurecimiento similares a los del objeto remachado, pero la dureza es menor en los remaches que en su respectiva hoja (Rovira y Gómez 2003; Aranda Jiménez et al. 2012: 159-161). Paralelamente, al ser la composición química de los procedentes del Sudeste y del Levante cobre puro o, en algún caso, plata tienen menor dureza que las correspondientes hojas (Montero 1991: 472-473; Simón 1998: 249250; Aranda Jiménez et al. 2012: 156-158). El único remache analizado en el nordeste procede de un contenedor de bronce del Bronce Final encontrado en Cova G del Cingle Blanc (Arbolí, Tarragona) y su composición es igualmente cobre puro (Rovira et al. 1997: 363). Cabe esperar que fuera similar en los remaches empleados en los puñales.

Para detectar evidencias del metal vertido en la colada hemos analizado por fluorescencia de rayos $\mathrm{X}(E D-X R F)$ la superficie de la parte externa y de la matriz del molde. Se ha empleado el espectrómetro INNOV-X Alpha equipado con tubo de rayos X, instalado en el Museo Arqueológico Nacional (Madrid). Los tiempos de adquisición se fijaron en $40 \mathrm{seg}$. y los valores cuantitativos fueron calculados a partir de patrones certificados. Nuestra hipótesis era que mostraría un bronce relativamente rico en estaño de composición similar a la de los puñales de remaches del nordeste.

Los resultados han sido negativos, no se ha detectado indicio alguno de metal. En nuestra opinión ello no demuestra, en modo alguno, que el molde no se empleara en la fundición. Los datos actuales de experimentación con moldes metalúrgicos prueban las limitaciones de este tipo de análisis. En las coladas de bronce vertidas en moldes de arcilla, el cobre aparece en valores sensiblemente menores que los originales y el estaño puede incluso no detectarse (Kearns et al. 2010). A la vez, los resultados del análisis de moldes arqueológicos con evidencias de uso son dispares: se obtienen datos negativos para moldes sin ninguna duda empleados (Craddock et al. 1997). Todos los investigadores recomiendan multiplicar los estudios en este campo. Las termoalteraciones identificadas en el molde de Camp Cinzano así como su correspondencia morfomé- trica con dos puñales de remaches apoya la propuesta de su utilización para la fundición durante el Bronce Inicial.

\section{MOLDES EN LA PENÍNSULA IBÉRICA. PRESENCIAS Y AUSENCIAS}

La amplia representación de objetos metálicos cortantes en la Península Ibérica contrasta con la parquedad de datos referentes a sus moldes. Antes del Bronce Final no tenemos constancia de ejemplares para espadas aunque sí para alabardas, procedentes fundamentalmente del área argárica (Simón 1998: 42; Brandherm 2003: 1531-1533; Delgado y Risch 2008: 245). Las matrices para puñales están igualmente poco representadas. Además del ejemplar de Camp Cinzano, hemos documentado cuatro más. Todos ellos proceden de asentamientos, son de arenisca y están fragmentados. Dos son del tipo univalvo, desconocemos si abierto o cerrado, y el otro par bivalvos (Figs. 5 y 6) (5).

El molde de Mola Alta de Serelles (Alcoi, Alicante) es el más parecido al ejemplar catalán, a pesar de que la matriz únicamente conserva la punta del puñal. Su contexto estratigráfico es impreciso, pudiendo ubicarse en algún momento del Bronce Antiguo-Medio. Los indicios de producción metalúrgica son abundantes: ocho moldes más y fragmentos de escoria. Además hay un vaso geminado (Trelis 1984: 51; Simón 1998: 112). Otro posible paralelo se localizó en el interior de una naveta en Can Roig Nou (Felanitx, Mallorca). Es un molde con dos matrices en caras opuestas: una para posible puñal u objeto punzante y otra para un artefacto alargado acabado en punta (Roselló 1974). A diferencia del molde alicantino, tanto su tipología como los materiales recuperados en el contexto lo sitúan en un momento tardío (Naviforme II.A, c. 14001200 cal ANE). Dicha cronología no concuerda con la adscrita a los puñales de remaches baleá-

(5) Excluimos del listado un molde univalvo cerrado con su correspondiente tapa procedente de El Argar (Antas, Almería). Fue hallado en la estructura habitacional $\mathrm{M}$ con otros moldes y crisoles (Montero 1991: 207; Siret y Siret 2006: 160, lám. 27). La morfología de la matriz se acerca más a la de algunas hachas planas o incluso a la de los cinceles/escoplos argáricos. La localización del canal de vertido en la parte distal del posible puñal, y no en la proximal, tampoco concuerda con los moldes que conocemos para este tipo de objetos. 


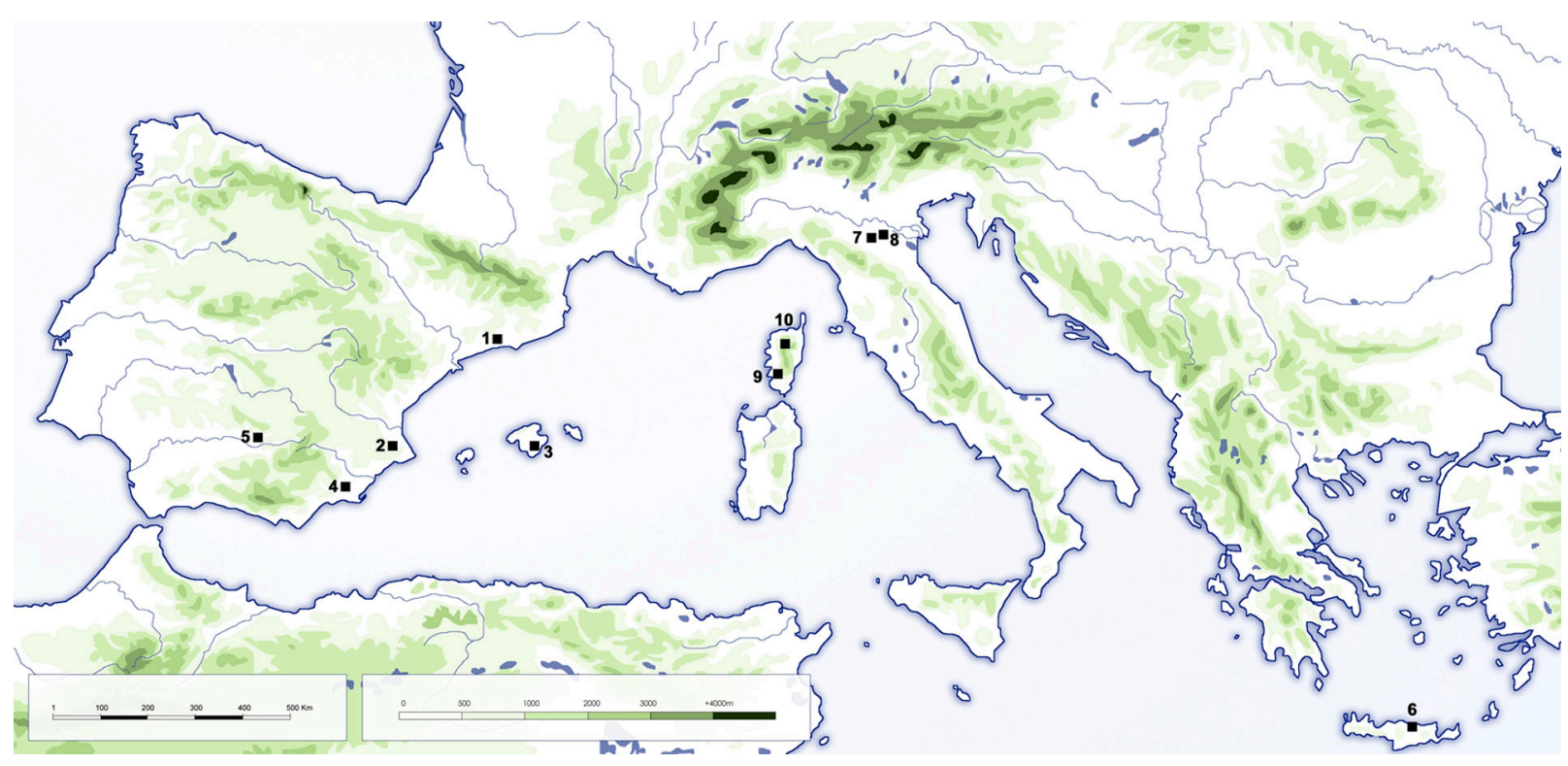

Fig. 5. Distribución de yacimientos con moldes para puñales, según el orden enumerado en el texto. En la Península Ibérica: 1. Camp Cinzano (Vilafranca del Penedès, Alt Penedès, Barcelona); 2. Mola Alta de Serelles (Alcoi, Alicante); 3. Can Roig Nou (Felanitx, Mallorca); 4. Las Anchuras (Totana, Murcia); 5. Peñalosa (Baños de la Encina, Jaén). Sitios extrapeninsulares: 6. Poros-Katsambas (Heraklion, Creta, Grecia); 7 y 8. Gorzano (Maranello) y Puglia di Redù (Nonantola)(Módena, Emilia Romaña, Italia); 9. Nebbiu (Filitosa, Córcega del Sur, Francia); 10. Castellu di a Marza (Corscia, Alta Córcega, Francia).
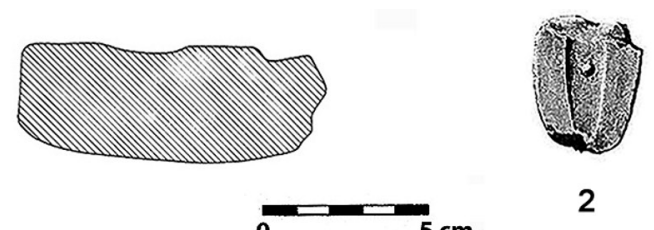

2

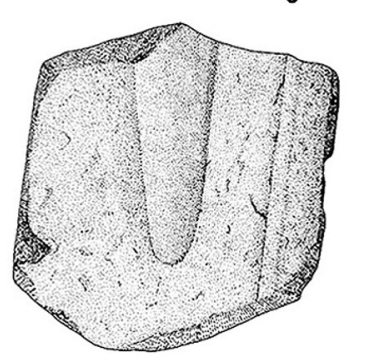

1

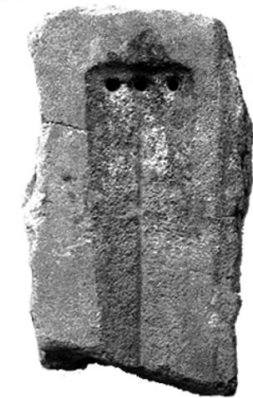

3
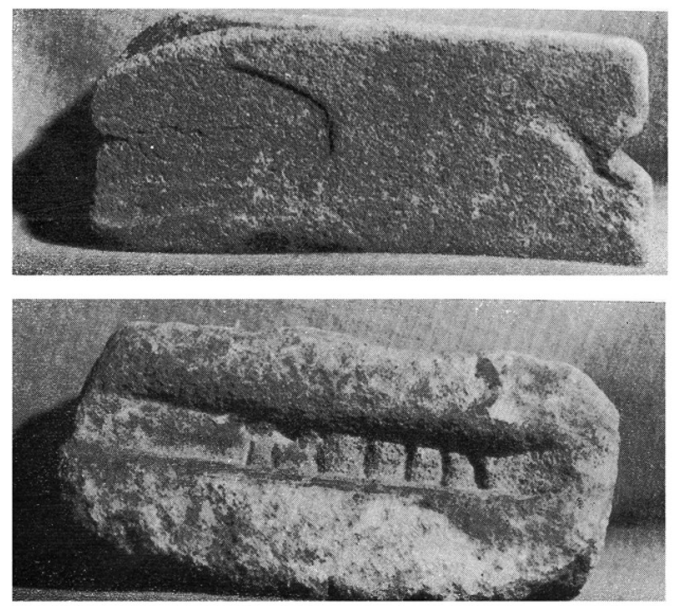

4

Fig. 6. Moldes para puñales de la Península Ibérica: 1. Mola Alta de Serelles (Alcoi, Alicante) (Simón 1998: 117); 2. Las Anchuras (Totana, Murcia) (Siret y Siret 2006: fig. XIII); 3. Peñalosa (Baños de la Encina, Jaén) (Moreno y Contreras 2010: 65); 4. Can Roig Nou (Felanitx, Mallorca) (Roselló 1974) (escala desconocida).

ricos, que se sitúan durante el Bronce Antiguo y Naviforme I (c. 2000-1400 cal ANE) (Salvà 2013: 489-491, 531-532). Ello, unido al carácter fragmentario de la matriz, sugiere que quizás nos encontremos ante un molde para lanza de espigón y hoja triangular, objeto más común en este período en las Islas Baleares (B. Salvà, com. per.). 
El primer molde bivalvo que consideramos procede de Las Anchuras (Totana, Murcia) y carece de contexto estratigráfico (Siret y Siret 2006: 124). La matriz corresponde a un puñal de lengüeta con un remache central, cuyo orificio se obtiene mediante un botón o protuberancia en positivo en la única valva recuperada del molde. En origen puede que existiera otro remache alineado verticalmente: tales puñales están documentados (véase infra) y el molde está fragmentado. Sin negar una posible adscripción calcolítica (Montero 1999: 341), hay puñales de morfología similar con una o dos perforaciones en contextos plenamente argáricos, como el yacimiento epónimo (Brandherm 2003: 171-177, láms. 25 y 26). De Peñalosa (Baños de la Encina, Jaén) proceden dos ejemplares y un molde con una cronología más precisa: c. 1750 cal ANE (fase IIIA del poblado). Un puñal con un remache formaba parte del ajuar funerario de la tumba 15a o de la 15b, ambas en urna con un individuo infantil de 3-4 años (complejo estructural IIIB). Otro con dos remaches alineados verticalmente se localizó en un pasillo asociado con las viviendas VIIA y VIIB (complejo estructural VIIj) (Contreras 2000: 218.31, 287.27). La matriz del puñal presenta nervadura central y tres agujeros para remaches que la atraviesan, características que demuestran su carácter bivalvo aun faltando la otra pieza. Fue localizado en un espacio destinado a la transformación y el almacenamiento de alimentos, pero donde otros moldes y mineral de cobre documentaron también labores metalúrgicas (complejo estructural XA) (Contreras 2000: 218.35; Moreno y Contreras 2010: 65).

En la Península Ibérica antes del Bronce Final únicamente se documentan los moldes de un conjunto muy concreto de objetos. Hachas, varillas y cinceles son los artefactos metálicos más representados, mientras que los moldes para puntas de flecha, punzones, brazaletes y cuentas son anecdóticos o inexistentes (6). Los datos metalográficos agravan esta problemática, ya que más de 200 piezas peninsulares analizadas habrían sido moldeadas (Hunt 2003: 380-385; Rovira y Gómez 2003: 159-167; Rovira y Delibes 2005: 502; Rodríguez Bayona 2008: 234-243). Ante esta situa-

(6) Fraile, A. Moldes de fundición de la Edad del Bronce en la Península Ibérica: Ensayo tipológico y cartográfico. Trabajo de Investigación de Tercer Ciclo, Universidad de Valladolid, 2007. ción caben dos hipótesis en parte compatibles: el acabado mediante forja de las preformas metálicas y el uso de moldes fabricados con arena compactada.

Los moldes para varillas podrían facilitar las preformas, mas tarde martilleadas en frío hasta alcanzar la morfología deseada. Esta hipótesis se ha propuesto para diferentes áreas peninsulares (Simón 1998: 314; Hunt 2003: 379-380; Rovira Hortalà 2006). Creemos que esta hipótesis solo sería aplicable para artefactos con poco trabajo postfundición, es decir, con cuerpo formado por un vástago. Los puñales y puntas de flecha quedarían excluidos. Según los datos metalográficos y experimentales actuales hay límites para el conformado mediante forja en frío. El cobre puro, incluso con cantidades importantes de arsénico, no puede modificarse más allá del $85 \%$ de su tamaño original, reduciéndose la transformación en el bronce hasta el 30-45\% (Lechtman 1996; Ottaway y Wang 2004: 64). El metal resultante requeriría, inevitablemente, sucesivos recocidos reparadores para evitar su rápida rotura. Sin embargo las metalografías indican que la gran mayoría de los puñales de lengüeta y una parte importante de los de remaches y de las puntas de flecha no fueron recocidos. De hecho, la "receta" metalúrgica más empleada en la Península Ibérica fue la fundición seguida de la forja en frío (Rovira y Gómez 2003: 170-175).

La otra posible solución (Ottaway y Seibel 1998) (Fig. 7) implica fabricar moldes univalvos abiertos, rellenando un marco de madera con arena fina tamizada con una proporción específica de arcilla y agua. La matriz de los objetos se imprimiría con un alma de madera, hueso o incluso un objeto metálico preexistente. Tras su alimentación horizontal, la fuerte degradación del molde lo inutilizaría para sucesivos usos. La experimentación constata que la fabricación de nuevos moldes es rápida, sencilla y muy versátil (Ottaway y Wang 2004: 9-11; Soriano y Gutiérrez 2009). Los indicios arqueológicos del uso de estos moldes son limitados, dado que generan pocos residuos. En el ya citado asentamiento metalúrgico de Lède du Gurp con fechado absoluto c. 1650-1500 cal ANE, se identificaron pequeñas cantidades de arena extremadamente fina y termoalterada, diferente a la disponible localmente (Roussot-Larroque 1997: 38), y quizá procedente de la disgregación de moldes de arena tras el vertido. Otros indicios de gran interés son las 
almas de madera. Se recuperó la de un hacha plana en el asentamiento lacustre de Robenhausen (Zurich, Suiza) (Strahm 1994: 18) y las de 2 hachas, 1 martillo y 2 puntas de lanza en Tobermore (Derry, Irlanda) (Coles et al. 1978: 15; O’Faoláin 2004: 192). Todas coinciden con artefactos metálicos contemporáneos y se interpretan como modelos para realizar moldes de arcilla pero igualmente podrían haber sido empleadas en moldes de arena. Son datos excepcionales y no concluyentes pero creemos que suficientes para considerar su uso como posible explicación de la ausencia de moldes para determinados objetos metálicos.

\section{UNA MIRADA HACIA EUROPA. RELACIONES E INTERACCIONES DURANTE LA EDAD DEL BRONCE}

En el contexto más amplio de Europa Occidental los moldes para puñales son igualmente minoritarios en relación a los existentes para otros objetos. Varían la tipología de sus matrices y su materia prima. Sin pretender ser exhaustivos tenemos constancia de ejemplares aislados en Escocia (Cowie y O'Connor 2009), Irlanda (Tylecote 1962: 112; Harbison 1969: 25), Países Bajos (Kuijpers 2008: 137), Eslovaquia (Vládar 1974: 40), Moravia (Gerloff 1975: 31), Alemania, Rumanía

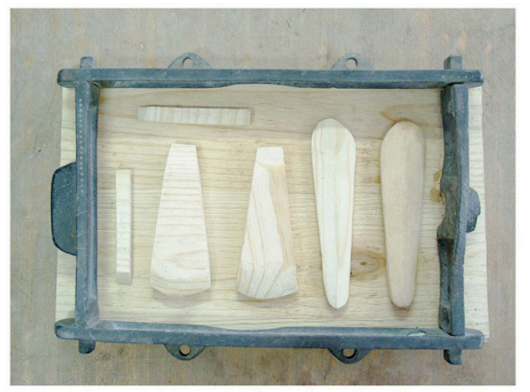

$\mathbf{1}$

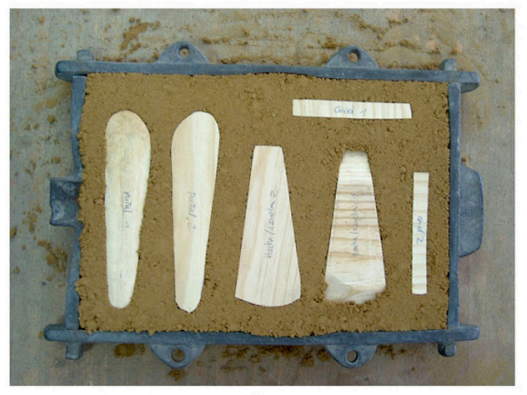

4

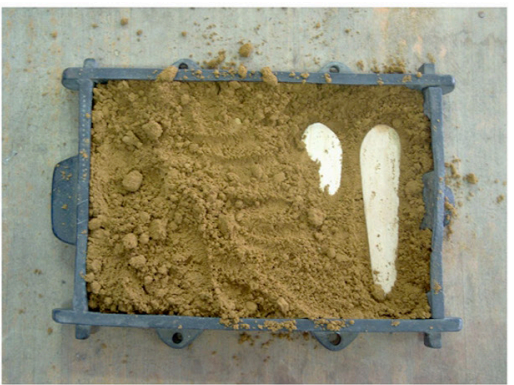

2

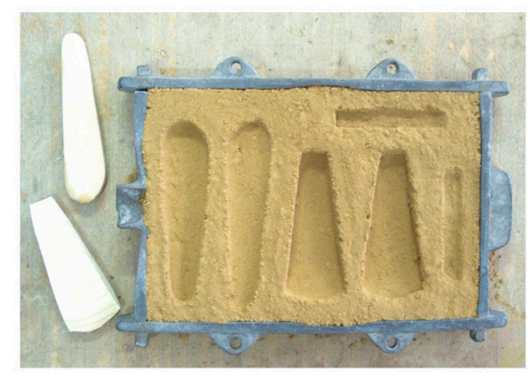

5

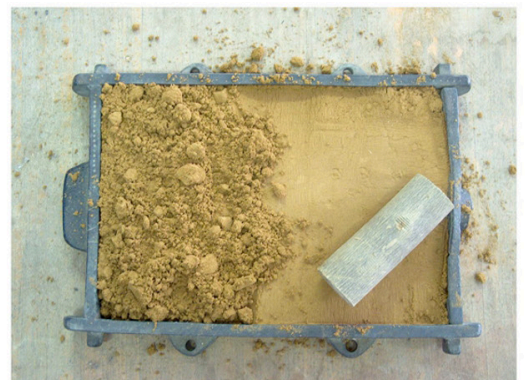

3

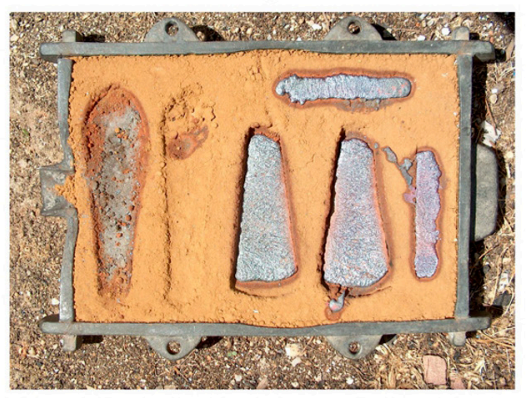

6

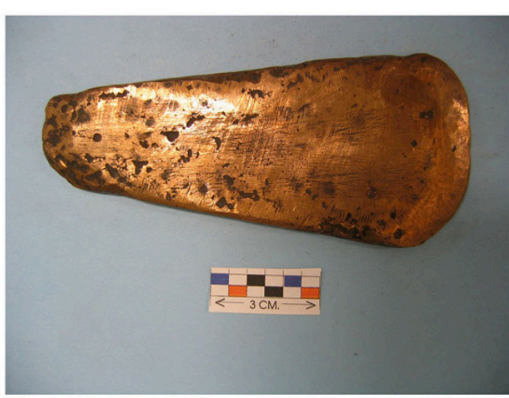

7

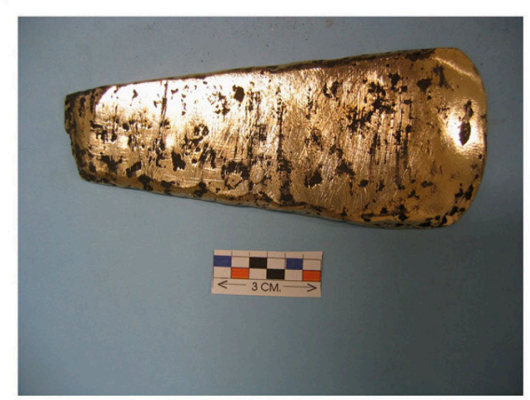

8

Fig. 7. Proceso experimental de fabricación y uso de un molde de arena compactada de tipo univalvo abierto: 1. a 3. Recubrimiento con arena de almas de madera en una coquilla metálica; 4. y 5. Aspecto del molde con las almas de madera y una vez extraídas; 6 . Apariencia de los objetos metálicos tras el vertido y proceso de degradación del molde; 7. y 8 . Objetos metálicos finales tras un proceso de desbastado, forja, recocido y pulido (bronce al $5 \%$ y $12 \%$ de estaño respectivamente) (fotografías Ignacio Soriano). 
y Chipre (Tylecote 1987: 214-215). Nos detenemos más en los que muestran cierta afinidad cronocultural con el ejemplar estudiado (Fig. 5 y 8). En nuestra opinión los datos justifican abrir un debate sobre el probable origen de estos moldes en el nordeste de la Península Ibérica.

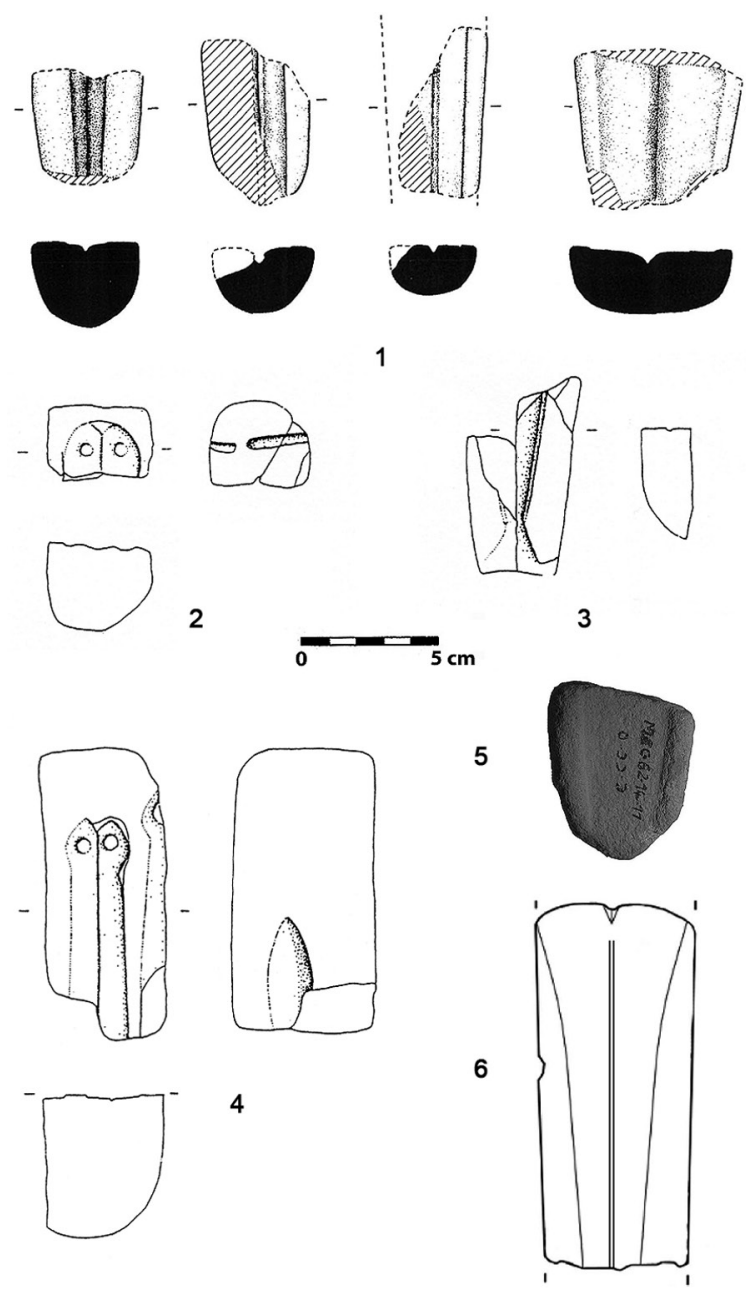

Fig. 8. Moldes para puñales del borde septentrional de la cuenca mediterránea: 1. Poros-Katsambas (Heraklion, Creta, Grecia); 2. y 3. Gorzano (Maranello) y 4. Puglia di Redù (Nonantola) en Módena (Emilia Romaña, Italia); 5. Nebbiu (Filitosa, Córcega del Sur, Francia); 6. Castellu di a Marza (Corscia, Alta Córcega, Francia). 1. a partir de Doonan et al. (2007: 108), 2. a 4. a partir de Le FèvreLehöerff (1992: 219 y 235), 5. y 6. según Peche-Quilichini et al. (e.p).

Los moldes más antiguos y, a la vez, alejados del área de estudio provienen del Egeo, específi- camente de Creta. El asentamiento minoico de Poros Katsambas presenta las primeras evidencias de producción metalúrgica de la isla: crisoles, restos de fundición y moldes. Hay 6 ejemplares bivalvos de arcilla para puñales con y sin nervadura central (4 y 2 respectivamente). Las matrices concuerdan con puñales metálicos de remaches ampliamente documentados en la isla. Los contextos de hallazgo se sitúan a inicios de la Edad del Bronce o período Prepalacial, es decir, entre finales del Minoico Antiguo I e inicios del Minoico Antiguo IIA (c. 3200-2600 cal ANE) (Doonan et al. 2007: 107-109).

En un momento algo posterior, en el norte de Italia se constata algún molde de puñal vinculado con los grupos calcolíticos de Remedello (c. 3300-2400 cal ANE), aunque tipológicamente se corresponde con un puñal de lengüeta (Rossi y Gattiglia 2005: 267). No hemos documentado ningún ejemplar asociado con los posteriores grupos campaniforme (2400-2200 cal ANE) y Polada (c. 2200-1600 cal ANE). Sin embargo no descartamos que hubieran existido, dadas las relaciones constatadas en el ámbito metalúrgico entre Italia y el Egeo (véase infra) y su continuidad en la tecnología metalúrgica de las Terramaras (Carancini 2004). Dichos grupos (c. 16001325 cal ANE) tienen también moldes para puñales. Citamos tres casos con cierta afinidad tipológica con el molde estudiado. Todos son bivalvos de piedra y proceden de la región de Módena (Emilia Romaña). Los dos primeros, recuperados en Gorzano (Maranello), podrían corresponder a una única pieza. En la matriz de uno solo se ve un fragmento del filo pero en la del otro se observan con claridad los botones en positivo para la posterior colocación de dos remaches. El tercero procede de Puglia di Redù (Nonantola) y presenta dos matrices para puñales, una con idénticos botones para los remaches (Le Fèvre-Lehöerff 1992: 161; Marzatico 1997: 580).

No conocemos casos en Cerdeña. En Córcega la mayor parte de los moldes para puñales suelen situarse a finales de la Edad del Bronce o ya en la Edad del Hierro. Destacamos dos excepciones de contexto impreciso. El primero (MC-62-1411) probablemente fue recuperado en el asentamiento turriforme de Nebbiu (Filitosa, Córcega del Sur). La matriz, realizada en granito, podría corresponder a la parte medial de un puñal, muy similar al de Camp Cinzano, aunque no es descartable que perteneciera a un hacha plana del 
Bronce Antiguo. El segundo de esteatita procede del hábitat fortificado de Castellu di a Marza (Corscia, Alta Córcega). Muestra la parte proximal de un puñal con nervadura central. Su tipología se ha puesto en relación con la de los puñales de remaches distribuidos por Italia durante toda la Edad del Bronce, aunque también en la Primera Edad del Hierro (Peche-Quilichini et al. e.p.).

Según los datos actuales sobre el Bronce Inicial en el nordeste de la Península Ibérica estamos ante un período de amplias relaciones e interacciones con otros grupos peninsulares y de otras zonas europeas. Estas superan la producción metalúrgica, abarcando otros ámbitos de la cultura material y de las prácticas sociales (Soriano 2013b: 155-160). No sorprende, pues, localizar el origen de la tecnología del molde de Camp Cinzano a cierta distancia del área de estudio. Consideramos que existen argumentos suficientes para proponer dos zonas hipotéticas de llegada de dicha tecnología: el Levante de la Península Ibérica y el norte de Italia. El conjunto de datos y, especialmente, su cronología nos hacen decantarnos por la segunda hipótesis.

Ya se ha expuesto la similitud morfológica y cronológica entre el molde de Camp Cinzano y el levantino de Mola Alta de Serelles. En dicho asentamiento se recuperaron varios vasos geminados, tipo cuya máxima concentración y posible origen se sitúa en la actual provincia de Valencia, pero documentado desde Alicante hasta Navarra (Sesma et al. 2007-2008). Esta cerámica también aparece en el nordeste, siempre al sur del río Llobregat. Además del ejemplar de Camp Cinzano, se conocen en yacimientos cercanos (Cova Verda, Cova dels Assedegats) (Maya 2002: 2324). Su cronología se sitúa c. 2200-1650 cal ANE y en algún caso presenta decoración epicampaniforme del Grupo del Nordeste. Dicha decoración, típica del Bronce Inicial en el área de estudio, abarca aproximadamente los mismos siglos. Su distribución supera las fronteras de Cataluña y se extiende hasta Huesca con ejemplares por la costa valenciana. Existen otras cerámicas muy presentes en el Levante cuya aparición en el nordeste se atribuye a las relaciones entre sus poblaciones. Nos referimos a las cerámicas con impronta basal de estera vegetal y a los vasos con cazoleta interna al lado del asa. Ambas se asignan por cronología arqueológica al II milenio cal ANE y se documentan, entre otros, en yacimientos cercanos al estudiado (Cova Verda, Esquerda de les Roques del Pany, Cova Fonda de Salomó) (Rovira Port 2006a, 2006b).

Los materiales óseos y metálicos aportan datos menos concluyentes. Los botones prismáticos de sección triangular y perforación en ' $\mathrm{V}$ ', situados en el III y II milenio cal ANE, se ubican principalmente en Cataluña, Baleares y sur de Francia y, de modo ocasional, en el Levante, valle del Ebro, Sudeste o Submeseta Sur (López Padilla 2006). Algunos investigadores interpretan parte de estos adornos como elementos foráneos llegados desde el nordeste (Uscatescu 1992: 7483). En relación al metal, la Cova d'Aigües Vives (Olius, Barcelona) es un ejemplo paradigmático de yacimiento con artefactos de procedencia muy diversa (Soriano 2013a: 102-105). Destacamos un puñal de remaches de cobre y una punta de flecha de bronce. El puñal es el único de todo el nordeste sin esta composición, típica de los objetos metálicos de la Edad del Bronce en Cataluña y el Valle del Ebro. En contrapartida, en los grupos contemporáneos del Levante, Sudeste o Suroeste los puñales sí son mayoritariamente de cobre puro (Rovira et al. 1997; Simón 1998: 246-253). La punta de flecha de tipo cónico pedunculado es otro elemento atípico tanto en el área de estudio como en la Península Ibérica. Solo conocemos un ejemplar similar, en cobre o bronce, de procedencia desconocida, perteneciente a la colección Cazurro del Museo de Prehistoria de Valencia (n. ${ }^{\circ}$ inv. 3039). Había permanecido inédito en sus fondos hasta fecha muy reciente (Soriano 2013b: 118). Las demás piezas que nos constan son óseas. Algunas se localizan en cavidades catalanas sin contexto estratigráfico. Otras proceden de la Cueva del Moro (Olvena, Huesca) y se sitúan en cronología absoluta en el primera mitad del II milenio cal ANE (Rodanés 1987: 89-94). Finalmente fuera de la Península Ibérica se documentan en metal en el grupo de las Terramaras del norte de Italia (Provenzano 1997).

Hay indicios probados de las interacciones entre los grupos de Polada y, posteriormente, Terramaras de Italia septentrional con los del área de estudio. Corresponden fundamentalmente al ámbito metalúrgico. La aguja con cabeza discoidal decorada de Cova del Toll (Moià, Bages), única en toda la Península Ibérica, tiene paralelos evidentes en los grupos de Polada aunque también en los centroeuropeos de Unetice y grupo 
del Ródano (Soriano 2013b: 139). Las hachas de rebordes son un elemento menos controvertido. Se conocen desde Francia a Europa Central y en Italia desde los grupos calcolíticos de Remedello y Rinaldone (Carancini 2004). En la Península Ibérica los ejemplares se concentran en el nordeste y raramente sobrepasan el límite del Ebro. Otros útiles, cada vez más identificados en el área de estudio en los últimos años, son los crisoles con pico vertedor y enmangue. Este es de dos tipos: con perforación para introducir un mango de madera y con un pie macizo de base plana. Los primeros se han recuperado en Minferri (Juneda, Lleida) (Soriano 2013b: 66-67), Cantorella (Maldà, Lleida) (Escala et al. e.p.) y Can Roqueta II (Sabadell, Barcelona) (Rovira Hortalà et al. 2007). Respecto a los segundos, existe un ejemplar en este último yacimiento y otro, en proceso de estudio por uno de nosotros (I. S.), en Can Mur (Valldoreix, Barcelona), un asentamiento inédito que fue parcialmente afectado en los años 1970 durante las obras de una vivienda particular. Sus paralelos son similares a los propuestos para el molde de Camp Cinzano. En el IV y III milenio cal ANE se emplean ejemplares de ambos tipos de crisoles sobre todo en Grecia continental y Creta con piezas aisladas en el norte de Italia, Córcega y Cerdeña entre otras zonas (Tylecote 1976: 18-20, 1987: 184; Camps 1990-1991: 4244; Doonan et al. 2007: 104; Evely et al. 2012: 1822). Los paralelos más próximos adscritos a la Edad del Bronce están en el norte de Italia, en el asentamiento poladiense de Fiavè 3 (Trentino, Alto Adagio) (Perini 1987: 35). Otros ejemplares más tardíos se vinculan con las Terramaras o provienen del ya comentado asentamiento de Lède du Gurp en el sur de Francia (Marzatico 1997: 585; Cierny et al. 2002). En la Península Ibérica los únicos crisoles similares proceden de Peña de la Dueña (Teresa, Castellón). Corresponden al primer tipo y han sido fechados por cronología arqueológica en un momento avanzado del II milenio cal ANE, a finales del Bronce Pleno o inicios del Bronce Tardío (Simón 1998: 317-321).

La problemática de la introducción de la tecnología del bronce en el área de estudio se añade a la confluencia de similitudes expuesta. La reciente revisión del tema ha evidenciado que la metalurgia del área catalana y del Valle del Ebro es mayoritariamente broncínea, en contraste con la de la mayoría de los grupos peninsulares de inicios de la Edad del Bronce (Soriano 2013b: 160).

Las fechas más antiguas de su producción se vinculan al grupo campaniforme y proceden de Balma del Serrat del Pont (Tortellà, Girona). Son restos de colada y fragmentos de un mínimo de 18 vasijas de reducción, lisas y con decoración campaniforme, aunque en este caso la aleación es accidental, fruto de las mineralizaciones empleadas (Alcalde et al. 1998: 92-97). La datación C14 de estas evidencias podría situarse c. 2750-2600 cal ANE, pero advertimos que el yacimiento tiene importantes problemas estratigráficos (Soriano 2013b: 19-20). Hasta el Bronce Inicial no aparecen las primeras evidencias de producción intencionada de bronce (Tab. 2). Proceden de Minferri (c. 2000-1800 cal ANE) y están relacionadas con el primer uso de moldes de piedra en el área de estudio así como con los ya citados crisoles con perforación (Equip Minferri 1997; GIP 2002).

Ligeramente más tardías son las de Monte Aguilar (Bárdenas Reales, Navarra), yacimiento donde se recuperaron restos de fundición y varios objetos de bronce (Sesma y García 1993-1994; Fernández-Miranda et al. 1995: 63). La ausencia de datos que indiquen un proceso previo de experimentación así como la documentación de instrumental metalúrgico en Minferri sugieren la introducción foránea de esta aleación. En otras regiones de la Península Ibérica como la Submeseta Norte también hay indicios de su uso temprano, caso del par de punzones de bronce de Cueva Maja (Cabrejas del Pinar, Soria) (Samaniego et al. 2001: 85-87).

En el resto de Europa desde mediados-finales del III milenio cal ANE emplean el bronce diferentes grupos con relaciones metalúrgicas atestiguadas. Las regiones más cercanas al área de estudio son el norte de Italia (grupos de Remede1lo, Rinaldone y posteriormente Polada) y el oeste de Francia (Túmulos Armoricanos) (Pare 2000: 23-25). También se conocen objetos de bronce aislados en el sur de Francia durante el Bronce Antiguo. Se trata del hacha plana de Tout de Faure (Lot, Mediodía-Pirineos) y de varios puñales de remaches de sepulcros megalíticos del mismo departamento y del de Pirineos Atlánticos (Aquitania) (Fernández-Miranda et al. 1995: 6062). Con el sur del país galo el nordeste comparte, además de los citados botones prismáticos triangulares con perforación en ' $\mathrm{V}$ ', la cerámica epicampaniforme de tipo barbelé (Lemercier et 
al. 2007). En cambio faltan moldes para puñales y crisoles con enmangue en esas fechas (Cert 2000). Creemos plausible que, si esta tecnología se introdujo atravesando tierras francesas, procediera del norte de Italia y, en concreto, de los grupos de Polada. Es muy notable que en el nordeste la primera metalurgia del bronce coinci$\mathrm{da}$, cronológica y espacialmente, con el uso de moldes de piedra y crisoles con orificio para el enmangue y pico vertedor. Los dos utensilios están estrictamente relacionados por la versatilidad en el manejo que aporta un crisol de estas características y la precisión que exige el vertido en un molde de alimentación vertical con un bebedero estrecho. El empleo sincrónico de ambos y del bronce está constatado en los grupos norditalianos de inicios de la Edad del Bronce.

\section{RECAPITULACIÓN}

El molde para puñales de Camp Cinzano constituye un elemento atípico y excepcional de la metalurgia de la Edad del Bronce. La datación absoluta de su contexto de hallazgo permite fecharlo c. 1850 cal ANE, próximo a las restantes evidencias metalúrgicas del territorio. Los paralelos documentados en la Península Ibérica son escasos. El más afín procede del yacimiento alicantino de Mola Alta de Serelles. Durante este período se detectan numerosas relaciones entre las comunidades del nordeste y del Levante peninsular a través de objetos cerámicos $\mathrm{y}$, de forma menos concluyente, artefactos óseos y metálicos. Del mismo modo se constatan interacciones entre el área de estudio y el norte de Italia, quizás incluyendo el sur de Francia como zona de paso y teniendo el Egeo como antecedente más destacable. Dichas evidencias, focalizadas en el ámbito metalúrgico, se refieren a la introducción de la aleación de bronce, de los crisoles con sistema de enmangue, de los moldes líticos y de ciertos objetos metálicos. Su cronología más antigua en la Península Italiana apunta a que, con mayor probabilidad, debamos ubicar allí el origen de la tecnología del molde estudiado. Es posible que las relaciones constatadas con el Levante fueran las responsables de la llegada desde el nordeste de este tipo de molde y, quizás también, de los crisoles con perforación de Peña de la Dueña. Esperemos que en el futuro pueda profundizarse en esta y otras problemáticas vinculadas con determinados útiles metalúrgicos prehistóricos, existentes en la Península Ibérica.

\section{AGRADECIMIENTOS}

A Ignacio Montero (Centro de Ciencias Humanas y Sociales, Consejo Superior de Investigaciones Científicas, Madrid) por su colaboración y soporte técnico. A Vicente Lull y Nicolás Escanilla (Universidad Autónoma de Barcelona), Dirk Brandherm (Queen's University Belfast), Kewin Peche-Quilichini (Université de Provence, LAMPEA-UMR 7269 CNRS) y Bartomeu Salvà (Universitat de les Illes Balears) por la información y comentarios proporcionados. A Jordi Farré, conservador del VINSEUM - Museo de las Culturas del Vino de Cataluña, por las facilidades prestadas en el estudio del molde. A los dos evaluadores anónimos por la revisión y comentarios a este artículo.

\section{BIBLIOGRAFÍA}

Alcalde, G.; Molist, M.; Montero, I.; Planagumà, L1.; Saña, M. ${ }^{\text {a }}$ y Toledo, A. 1998: "Producciones metalúrgicas en el nordeste de la Península Ibérica durante el III milenio cal. AC: el taller de la Bauma del Serrat del Pont (Tortellà, Girona)". Trabajos de Prehistoria 55 (1): 81-100.

Amorós, J. 2008: Memòria de la intervenció arqueolòica preventiva al Camp Cinzano 2004-2005 (Vilafranca del Penedès, Alt Penedès). Servei d'Arqueologia i Paleontologia, Generalitat de Catalunya. Vilafranca del Penedès. http://www20. gencat.cat/docs/CulturaDepartament/DGPC/Documents/memories\%202009/qmem6970.pdf (consulta 4-VIII-2014).

Aranda Jiménez, G.; Alarcón García, E.; MurilloBarroso, M.; Montero Ruíz, I.; Jiménez-Brobeil, S.; Sánchez Romero, M. y Rodríguez-Ariza, M. O. 2012: "El yacimiento argárico del Cerro de San Cristóbal (Ogíjares, Granada)". Menga 3: 141-166.

Boquer, S.; Bosch, J.; Cruells, W.; Miret, J.; Molist, M. y Rodón, T. 1995: El jaciment de l'Institut de Batxillerat Antoni Pous. Un assentament a l'aire lliure de finals del calcolitic (Manlleu, Osona). Memòries d'Intervencions Arqueològiques a Catalunya 15 , Generalitat de Catalunya. Barcelona.

Bouso, M.; Esteve, X.; Farré, J.; Feliu, J. M.a.; Mestres, J.; Palomo, A.; Rodríguez, A. y Senabre, M. ${ }^{\mathrm{a}}$ R. 2004: "Anàlisi comparatiu de dos assentaments del Bronze Inicial a la depressió prelitoral catalana: 
Can Roqueta II (Sabadell, Vallès Occidental) i Mas d'en Boixos-1 (Pacs del Penedès, Alt Penedès)". Cypsela 15: 73-101.

Brandherm, D. 2003: Die Dolche und Stabdolche der Steinkupfer- und der älteren Bronzezeit auf der Iberische Halbinsel. Prähistorische Bronzefunde Abteinlung VI-Band 12. Ed. F. Steiner. Stuttgart.

Camps, G. 1990-1991: "Les creusets de Terrina (Aléria, Haute-Corse)". En: Colloque International Hommage au Dr. Jean Arnal. Le Chalcolithique en Languedoc. Archéologie en Languedoc 15: 41-49.

Carancini, G. L. 2004: "La metallurgia fusoria: organizzazione e centri della manifattura". En D. Cocchi Genick (ed.): L'età del bronzo recente in Italia. Atti del Congresso Nazionale di Lido di Camaiore (Lido di Camaiore 2000): 275-291. Viareggio.

Carlús, X.; López Cachero, J.; Terrats, N.; Oliva, M.; Palomo, T. y Rodríguez, A. 2008: "Diacronia durant la prehistòria recent a Can Roqueta (SabadellBarberà del Vallès, Vallès Occidental) entre el VI i el I mil·lenni cal ANE". Cypsela 17: 115-142.

Cert, C. 2000: "Les moules de métallurgistes dans les Pyrénées". Bulletin de la Société Préhistorique Française 97,4: 595-608.

Cierny, J.; Degasperi, N. y Frontini, P. 2002: "Castellaro del Vhò di Piadena (Cremona): strutture a cielo aperto del Bronze Medio". En A. Giumlia-Mair (ed.): I Bronzi Antichi: produzione e tecnologia. Atti del XV Congresso Internazionale sui bronzi antichi (Grado-Aquileia 2001). Monographies Instrumentum 21, Éd. Monique Mergoil. Montagnac: 44-51.

Coghlan, H. H. 1975: Notes on the Prehistoric Metallurgy of Copper and Bronze in the Old World. Occasional Papers on Technology 4, Pitt Rivers Museum. Oxford.

Coles, J. M.; Heal, S. V. E. y Orme, B. J. 1978: "The use and character of wood in prehistoric Britain and Ireland". Proceedings of the Prehistoric Society 44: 1-45.

Contreras, F. 2000: Análisis histórico de las comunidades de la Edad del Bronce del Piedemonte meridional de Sierra Morena y Depresión LinaresBailén. Proyecto Peñalosa. Monografías 10, Consejería de Cultura. Sevilla.

Cowie, T. y O'Connor, B. 2009: "Some Early Bronze Age Stone Moulds from Scotland". En T. L. Kienlin y B. W. Roberts (eds.): Metals and Societies. Studies in honour of Barbara S. Ottaway. Universitatsforschungen zur Prähistorischen Archäologie 169. Bonn: 313-327.

Craddock, P. T.; Freestone, I. y Dawe, C. D. 1997 : "Casting metals in limestone moulds". Journal of Historical Metallurgy Society 31, 1: 1-7.

Delgado, S. y Risch, R. 2008: "Lithic perspectives on metallurgy: An example from Copper and Bronze Age South-East Iberia". En L. Longo y N. Skakun (eds.): 'Prehistoric Technology' 40 Years Later: Functional Studies and the Russian Legacy. Proceedings of the International Congress Verona (Italy 2005). British Archaeological Reports, International Series 1783, Archaeopress. Oxford: 235-252.

Doonan, R. C. P.; Day, P. M. y Dimopoulou-Rethemiotaki, N. 2007: "Lame excuses for emerging complexity in Early Bronze Age Crete: the metallurgical finds from Poros Katsambas and their context". En P. M. Day y R. C. P. Doonan (eds.): Metallurgy in the Early Bronze Age Aegean. Oxbow Books, Sheffield Studies in Aegean Archaeology. Sheffield: 98-122.

Equip Minferri 1997: "Noves dades per a la caracterització dels assentaments a l'aire lliure durant la primera meitat del II mil-lenni cal. BC: primers resultats de les excavacions en el jaciment de Minferri (Juneda, les Garrigues)". Revista d'Arqueologia de Ponent 7: 161-211.

Escala, O.; Moya, A.; Tartera, E.; Vidal, A. y Armentano, N. e.p.: "Cantorella (Maldà, Urgell), un nou assentament a l'aire lliure del neolític final-calcolític i del bronze ple a la Vall del Corb". Tribuna d'Arqueologia 2011-2012.

Evely, D.; Hein, A. y Nodarou, E. 2012: "Crucibles from Palaikastro, East Greece: insights into metallurgical technology in the Aegean Late Bronze Age". Journal of Archaeological Science 39: 18211836.

Fernández-Miranda, M.; Montero, I. y Rovira, S. 1995: "Los primeros objetos de bronce en el Occidente de Europa". Trabajos de Prehistoria 52 (1): 57-69. doi:10.3989/tp.1995.v52.i1.431.

Fraile, A. 2011: "Moldes de fundición prehistóricos en la Península Ibérica: concepto y aspectos terminológicos". En J. M. Mata-Perelló, L. Torró i Abat y M. ${ }^{\mathrm{a}}$ N. Fuentes Prieto (eds.): Actas del Quinto Congreso Internacional sobre Minería y Metalurgia Históricas en el Suroeste Europeo (León 2008). Libro en Homenaje a Claude Domergue: 169-178. La Pobla de Segur.

Gerloff, S. 1975: The Early Bronze Age Daggers in Great Britain and a reconsideration of the Wessex Culture. Prähistorische Bronzefunde Abteinlung VI, 2, Beck. München.

Giró, P. 1954: "Nuevos sepulcros de fosa en Villafranca". Ampurias 15-16: 328-333.

Grup d'Investigació Prehistòrica - GIP 2002: Els colors de la Terra. La vida y la mort en una aldea d'ara fa 4000 anys. Minferri, Juneda. Quaderns de la Sala d'Arqueologia 1, Institut d'Estudis Ilerdencs. Lleida.

Harbison, P. 1969: The Daggers and the Halberds of the Early Bronze Age in Ireland. Prähistorische Bronzefunde Abteinlung VI, 1, Beck. München.

Hunt, M. A. 2003: Prehistoric mining and metallurgy in the SW Iberian Peninsula. British Archaeological 
Reports, International Series 1188, Archaeopress. Oxford

Kearns, Th.; Martinón-Torres, M. y Rehren, Th. 2010: "Metal to mould: alloy identification in experimental casting moulds using XRF". Historical Metallurgy 44 (1): 48-58.

Kuijpers, M. H. G. 2008: Bronze Age Metalwork in the Netherlands (c.2000-800 BC). Sidestone Press. Leiden.

Le Fèvre-Lehöerff, A. 1992: “Les moules de l'Age du Bronze Dans la plaine orientales du Po: vestiges de mise en forme des alliages base cuivre". Padusa 28: 131-244.

Lechtman, H. 1996: "Arsenic copper: dirty copper or chosen alloy? A view from the Americas". Journal of Field Archaeology 23 (4): 477-514.

Lemercier, O.; Leonini, V.; Tramoni, P. y Furestier, R. 2007: "Campaniformes insulaires et continentaux de France et d'Italie méditerranéennes. Relations et échanges entre Corse, Sardaigne, Toscane et Midi français dans la seconde moitié du troisième millénaire avant notre ère". En A. D'Anna, J. Cesari, L. Ogel y J. Vaquer (ed.): Corse et Sardaigne préhistoriques: relations et échanges dans le contexte méditerranéen. $128^{\circ}$ Congrès National des Sociétés Historiques et Scientifiques (Bastia 2003). Documents préhistoriques 22, Comité des Travaux historiques et scientifiques (C.T.H.S.). Paris: 241-252.

López Padilla, J. A. 2006: "Distribución territorial y consumo de botones de perforación en ' $\mathrm{V}$ ' en el ámbito argárico". Trabajos de Prehistoria 63 (2): 93-116. doi:10.3989/tp.2006.v63.i2.19.

Marzatico, F. 1997: “L'industria metallurgica nel Trentino durante l'età del bronzo". En M. Bernabò Brea, A. Cardarelli y M. Cremaschi (eds.): Le Terramare. La più antica civilità padana. Electa. Milano: 570591.

Maya, J. L. 1991: "El nordeste peninsular entre la Edad del Bronce y el mundo protoibérico". Boletín de la Asociación Española de Amigos de la Arqueología 30-31: 87-97.

Maya, J. L. 1992: "Calcolítico y Edad del Bronce en Cataluña”. En M. ${ }^{\mathrm{a}}$ del P. Utrilla Miranda (coord.): Aragón/Litoral Mediterráneo. Intercambios culturales durante la Prehistoria en homenaje a Juan Maluquer de Motes. Institución Fernando el Católico. Zaragoza: 516-554

Maya, J. L. 1997: "Reflexiones sobre el Bronce Inicial en Cataluña". Saguntum 30: 11-27.

Maya, J. L. 2002: "Relacions i contactes durant el Calcolític i l'Edat del Bronze a la Catalunya Meridional". Citerior 3: 17-46.

Maya, J. L. y Petit, M. a A. 1994: “L'Edat del Bronze a Catalunya. Problemàtica i perspectives de futur". En $X .{ }^{\circ}$ Col-loqui Internacional d'Arqueologia de Puigcerdà. Institut d'Estudis Ceretans. Puigcerdà: 327-342.
Montero, I. 1991: Estudio arqueometalúrgico en el Sudeste de la Península Ibérica. Tesis Doctoral, Universidad Complutense de Madrid. Madrid. http:// eprints.ucm.es/1835/ (consulta 5-VIII-2014).

Montero, I. 1999: "Sureste". En G. Delibes e I. Montero (eds.): Las primeras etapas metalúrgicas de la Península Ibérica II. Estudios regionales. Instituto Universitario Ortega y Gasset. Madrid: 323-357.

Moreno, A. y Contreras, F. 2010: "La organización social de la producción metalúrgica en las sociedades argáricas: el poblado de Peñalosa". Menga 1: 53-75.

Muñoz, A. M. ${ }^{\text {a } 1965: ~ L a ~ c u l t u r a ~ n e o l i ́ t i c a ~ c a t a l a n a ~ d e ~}$ los Sepulcros de Fosa. Instituto de Arqueología y Prehistoria, Universidad de Barcelona, Publicaciones Eventuales 9. Barcelona.

Ó Faoláin, S. 2004: Bronze Artefact Production in Late Bronze Age Ireland. A survey. British Archaeological Reports, British Series 382, Archaeopress. Oxford.

Ottaway, B. S. y Seibel, S. 1998: "Dust in the wind": experimental casting of bronzes in sand moulds". En M-Ch. Frére-Sautot (ed.): Paléometallurgie des cuivres. Actes du colloque de Bourg-en-Bresse et Beaune 17-18 octobre 1997. Monographies Instrumentum 5, Éd. Monique Mergoil. Montagnac: 59-63.

Ottaway, B. S. y Wang, Q. 2004: Casting experiments and microstructure of archaeological relevant bronzes. British Archaeological Reports, International Series 1331, Archaeopress. Oxford.

Palomo, A. 2006: "El Camí dels Banys de la Mercè (Capmany-Alt Empordà)". En 8. Jornades d'Arqueologia de les Comarques Gironines (Roses 2006) I: 63-72. Roses.

Pancorbo, A. y Piera, M. 2006: Memòria de l'excavació arqueolòica realitzada als Llirians del Mas, les Torres $i$ al sector Rec (Salàs de Pallars, Pallars Jussà) 14 d'octubre-13 de novembre de 2003, 1 de juny-9 de juliol de 2004. Servei d'Arqueologia i Paleontologia, Generalitat de Catalunya. Manresa. http:/calaix.gencat.cat/handle/10687/9474 (consulta 4-VIII-2014).

Pare, Ch. 2000: "Bronze and the Bronze Age". En C. F. E. Pare (ed.): Metals Make the World Go Round. The Supply and Circulation of Metals in Bronze Age Europe. Oxbow. Oxford: 1-38.

Peche-Quilichini, K.; Graziani, J.; Antolini J. F.; Gardella, M. A. y Milletti, M. (e.p.): "Les matrices de fusion protohistoriques de Corse: état de la recherche et découvertes récentes". En T. Perrin, I. Sénépart, F. Leandri y J. Cauliez (eds.): Chronologie de la Préhistoire Récente dans le Sud de la France. Acquis 1992-2012. Actualités de la recherche. Actes des Xes Rencontres Méridionales de Préhistoire Récente (Ajaccio 2012). 
Perini, R. 1987: Scavi archeologici nella zona palafitticola di Fiavè-Carera. Parte II. Campagne 19691976. Resti della cultura materiale. Metallo-ossolegno. Patrimonio Storico e Artístico del Trentino 9. Trento.

Piera, M. 2008: "El jaciment de la Vinya del Corb (Bassella, Alt Urgell)". En $1^{\text {er }}$ Col-loqui d'Arqueologia d'Odèn (Solsona 2006). La prehistòria avui en el Prepirineu lleidatà: 23-30. Solsona.

Provenzano, N. 1997: "Produzione in osso e corno delle terramare emiliane". En M. Bernabò Brea, A. Cardarelli y M. Cremaschi (eds.): Le Terramare. La più antica civilità padana. Electa. Milano: 524-540.

Rodanés, J. M. ${ }^{a}$ 1987: La industria ósea prehistórica en el Valle del Ebro: Neolitico-Edad del Bronce. Serie Arqueología Aragonesa 4, Diputación General de Aragón. Zaragoza.

Rodríguez Bayona, M. 2008: La investigación de la actividad metalúrgica durante el III milenio A.N.E. en el Suroeste de la Península Ibérica. La arqueometalurgia y la aplicación de análisis metalográficos y composicionales en el estudio de la producción de objetos de metal. British Archaeological Reports, International Series 1769, Archaeopress. Oxford.

Roselló, G. 1974: "Los ajuares metálicos mallorquines como elementos cronológicos". Prehistoria y Arqueología de las Islas Baleares. VI Symposium de Prehistoria Peninsular (Palma de Mallorca 1972). Universidad de Barcelona, Instituto de Arqueología y Prehistoria, Publicaciones Eventuales 24. Barcelona: 115-128.

Rossi, M. y Gattiglia, A. 2005: "Les poignards de Remedello hors d'Italie: révision de données". En P. Ambert y J. Vaquer (eds.): La première métallurgie en France et dans les pays limitrophes. Mémoire XXXVII de la Société Préhistorique Française. Joué-Lès-Tours: 265-271.

Roussot-Larroque, J. 1997: "La Lède du Gurp et la métallurgie du Bronze moyen dans le Médoc". Revue archéologique de Bordeaux 88: 33-56.

Rovira, S. y Delibes, G. 2005: "Tecnología metalúrgica campaniforme en la Península Ibérica: coladas, moldeado y tratamientos postfundición”. En M. A. Rojo-Guerra, R. Garrido-Pena y I. García-Martínez (eds.): El campaniforme en la Península Ibérica y su contexto europeo. Universidad de Valladolid. Valladolid: 495-512.

Rovira, S. y Gómez Ramos, P. 2003: Las Primeras Etapas Metalúrgicas en la Península Ibérica III. Estudios metalográficos. Instituto Universitario Ortega y Gasset. Madrid.

Rovira, S.; Montero, I. y Consuegra, S. 1997: Las primeras etapas metalúrgicas de la Península Ibérica I. Análisis de materiales. Instituto Universitario Ortega y Gasset, Ministerio de Cultura. Madrid.
Rovira Hortalà, M. ${ }^{a}$ C. 1998: “Activités métallurgistes à l'extrême nord-est de la Péninsule Ibérique pendant l'Age du Bronze Ancien-Moyen. Le site de Minferri (Lleida)". En C. Mordant, M. Pernot y V. Rychner (eds.): L'atelier du bronzier en Europe du XX au VIII siècle avant notre ère. Actes sur colloque international Bronze'96 Neuchâtel et Dijon, II: Production, circulation et consommation du bron$z e$. Comité des travaux historiques et scientifiques (C.T.H.S.). Paris: 241-248.

Rovira Hortalà, M. ${ }^{\mathrm{a}}$ C. 2006: "El Bronze Inicial a Catalunya des de la perspectiva metal-lúrgica". Cypsela 16: 135-145.

Rovira Hortalà, M. ${ }^{\mathrm{a}}$ C.; Palomo, A. y Rodríguez, A. 2007: "Metalurgia prehistórica en la Catalunya prelitoral: los instrumentos de broncista de Can Roqueta II (Sabadell, Barcelona)". En J. M. Mata-Perelló (ed.): Primer Congreso Internacional de Minería y Metalurgia en el contexto de la Historia de la Humanidad: Pasado, presente y futuro (Mequinenza 2006): 505-510. Mequinenza.

Rovira Port, J. 2006a: "El recipiente cerámico con cazoleta interna de la Cova Fonda (Salomó, Tarragona) y sus homólogos de la Península Ibérica. Sobre la relación entre el bronce valenciano septentrional y el bronce antiguo-medio de la Cataluña centro-meridional". Quaderns de Prehistòria $i$ d'Arqueologia de Castelló 25: 139-146.

Rovira Port, J. 2006b: "Las producciones cerámicas con impronta basal de estera vegetal del calcolítico final-bronce antiguo/medio de la Península Ibérica: acerca de la alternancia de influjos y el origen del protourbanismo en la depresión central catalana como modelo de territorio basculante". Quaderns de Prehistòria i d'Arqueologia de Castelló 25: 109137.

Salvà, B. 2013: Arqueometal-lúrgia com a réflex de l'estratificació social a les Illes Balears. Tesis Doctoral, Universidad de Barcelona. Barcelona. http:// hdl.handle.net/2445/53887 (consulta 5-VIII-2014).

Samaniego Bordiu, B.; Jimeno Martínez, A.; Fernández Moreno, J. J. y Gómez Barrera, J. A. 2001: Cueva Maja (Cabrejas del Pinar, Soria): Espacio y simbolismo en los inicios de la Edad del Bronce. Memorias 10, Arqueología en Castilla y León. Junta de Castilla y León. Valladolid.

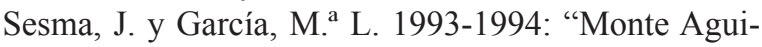
lar (Bardenas Reales de Navarra). Campañas de 1990-1991". Trabajos de Arqueología de Navarra 11: 276-280.

Sesma, J.; García, J. y Tabar, M.a I. 2007-2008: "Vasos geminados de la Edad del Bronce en Navarra". Veleia 24-25: 925-936.

Simón, J. L. 1998: La metalurgia prehistórica valenciana. Servicio de Investigación Prehistórica, Serie de Trabajos Varios 93. Valencia.

Trab. prehist., 71, N. ${ }^{\circ}$ 2, julio-diciembre 2014, pp. 368-385, ISSN: 0082-5638

doi: $10.3989 /$ tp. 2014.12140 
Siret, E. y Siret, L. 2006: Las primeras edades del metal en el sudeste de España. Dirección General de Cultura, Museo Arqueológico de Murcia. Murcia, $1 .^{\text {a }}$ ed. 1890.

Soriano, I. 2010: Producción metalúrgica prehistórica en el nordeste de la Península Ibérica (mediados del IV-II milenio cal ANE). Aportaciones cronoculturales, tecnológicas y funcionales. Tesis Doctoral, 2 vols. + CD Rom, Universidad Autónoma de Barcelona. Barcelona.

Soriano, I. 2011: "De tumbas de metalúrgicos en el Nordeste peninsular. El Forat de la Tuta (Riner, Solsonès)". Revista d'Arqueologia de Ponent 21: 37-56.

Soriano, I. 2013a: "El Solsonès y el Berguedà como encrucijada de caminos en el contexto europeo. Aportaciones desde la metalurgia y la orfebrería prehistórica (c. finales del IV-mediados del II milenio cal ANE". 3er Col-loqui d'Arqueologia d'Odèn (Cambrils, Odèn 2011): 99-108. Solsona.

Soriano, I. 2013b: Metalurgia y Sociedad en el Nordeste de la Península Ibérica (finales del IV-II milenio cal ANE). British Archaeological Reports, International Series 2502, Archaeopress. Oxford.

Soriano, I. y Gutiérrez, C. 2009: "Use-wear analysis on metal: the raw material and metallurgical work process influence". En Associazione Italiana di Metallurgia (ed.): $2^{\text {nd }}$ International Conference Archaeometallurgy in Europe 2007 (Aquileia-Italy 2007). Selected Papers: 115-124. Milan.
Strahm, Ch. 1994: "Die Anfänge der Metallurgie in Mitteleuropa". Helvetia Archaeologica 97: 2-39.

Subirà, M. ${ }^{\mathrm{a}}$ E. 2008: “Annex 1: Estudi antropològic de les restes excavades en la campanya de 2004 al jaciment de Cinzano (Vilafranca del Penedès)". En J. Amorós. Memòria de la intervenció arqueològica preventiva al Camp Cinzano 2004-2005 (Vilafranca del Penedès, Alt Penedès). Servei d'Arqueologia i Paleontologia, Generalitat de Catalunya, Vilafranca del Penedès: 180-201. http://www20.gencat.cat/ docs/CulturaDepartament/DGPC/Documents/memories\%202009/qmem6970.pdf (consulta 4-VIII2014).

Trelis, J. 1984: "El poblado de la Edad del Bronce de la Mola Alta de Serelles (Alcoy, Alicante)". Lucentum 3: 23-66.

Tylecote, R. F. 1962: Metallurgy in Archaeology. A prehistory of Metallurgy in the British Isles. Longman, Edward Arnold Ltd. London.

Tylecote, R. F. 1976: A history of metallurgy. The Metals Society. London.

Tylecote, R. F. 1987: The early history of metallurgy in Europe. Longman. London and New York.

Uscatescu, A. 1992: Los botones de perforación en ' $V$ ' en la Península Ibérica y las Baleares durante la Edad de los Metales. Foro. Madrid.

Vládar, J. 1974: Die Dolche in der Slowakei. Prähistorische Bronzefunde Abteinlung VI, 3, C.H. Beck. München. 